\title{
The impact of work experience of small and medium-sized enterprises owners or managers on their competitive intelligence awareness and practices
}

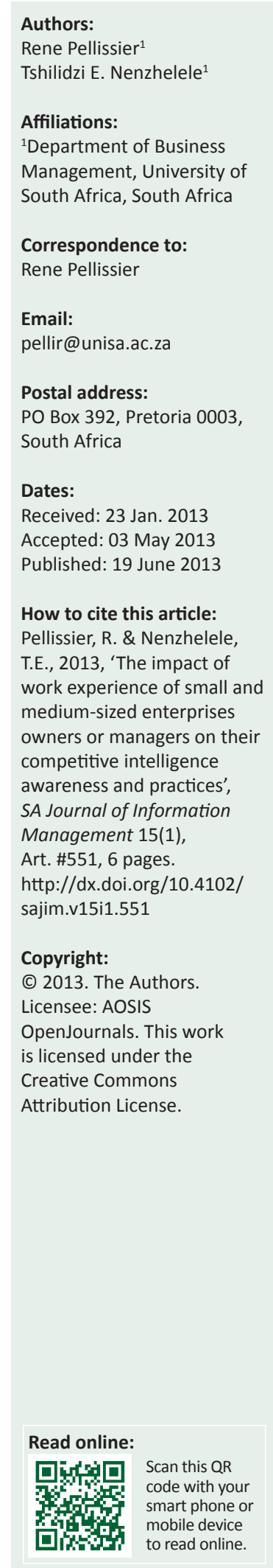

Background: Information technology has assisted in globalisation, which then assisted in making international trade easier. Consequently, businesses no longer compete with local competitors only but also with international ones, leading to intense competition in all business sectors. Businesses will hardly practice what they are not aware of and therefore needs to know about their competitive landscape. Competitive intelligence (CI) gathers information from both the internal and external business environments, and analyses these for use by decision makers. Whilst awareness of the importance of CI is wide, it is not practiced optimally, making the need for creating awareness of the benefits of $\mathrm{CI}$ important.

Objectives: The objective of this research was to establish the influence of owners' and managers' working experience of CI practice and awareness in the small and medium-sized enterprises (SMEs) environment.

Method: This research was quantitative in nature and a questionnaire was used to collect data from SMEs owners and managers in The City of Tshwane Metropolitan Municipality.

Results: This research indicates that SMEs in the study are aware of CI through education and training. Moreover, the study reveals that the working experience of owners and managers has a great influence on awareness and practice of CI and one should implement training programmes in this domain to assist with building competitive advantage.

Conclusion: Small and medium-sized enterprises owners or managers' years of working experience has a greater influence on awareness and practice of CI. Put differently, years of working experience is a great predictor of $\mathrm{CI}$ awareness and practice.

\section{Introduction}

Enterprises are faced with an increasingly competitive environment in which it is difficult to maintain a sustained competitive advantage (Shih, Liu \& Hsu 2010). Guarda, Augusto and Silva (2012) state that competitive advantage can be understood as seeking unique opportunities that will give the enterprise a strong competitive position. According to Shih et al. (2010), in order to sustain a competitive position, managers should be prepared to respond promptly to changes in customer preferences, competitor strategies and technological advancements. For these reasons, many enterprises - whether public or private, and small or large - initiate their own competitive intelligence (CI) services to inform and prepare managers for changes in the external environment of the enterprise (Taleghani, Rad \& Rahmati 2012; Bourret 2012). According to Deng and Luo (2010), CI plays an increasingly important role in the strategic management and decision-making of an enterprise. Muller (2007) indicates that the optimisation of CI by an enterprise requires an awareness and understanding of CI by the management of the enterprise.

The implementation and use of CI by SMEs has not been as well documented as in the case of larger enterprises (Tarraf \& Molz, 2006). Smith, Wright and Pickton (2010) reveal that there is a dearth in the literature regarding $\mathrm{CI}$ awareness and practices in SMEs. Although CI research on SMEs has been undertaken in countries such as China, France, Turkey, United States of America, Belgium, Canada, Switzerland, Japan, Sweden, Australia and India, it is lacking in South Africa (Smith, Wright \& Pickton 2010; Koseoglu et al. 2011). The purpose of this research is to establish the effect of the working experience of managers on CII awareness and practices in SMEs.

\section{Small and medium-sized enterprises}

The importance of SMEs in creating jobs and economic wealth is globally recognised (Olawale \& Garwe 2010). SMEs employ more than $95 \%$ of the world's working population and are the main source of employment in developing countries (Abor \& Quartey 2010). As a result, governments 
throughout the world focus on the development of the SME sector to promote economic growth (Olawale \& Gware 2010). Olawale and Gware (2010) reveal that in South Africa, SMEs contribute $56 \%$ of the employment in the private sector and $36 \%$ of the gross domestic product (GDP). However, gaining a competitive advantage presents an enormous challenge for SMEs. Prior (2007) is of the opinion that SMEs have many competitors that offer similar products or services and operate in the same markets and locations. Moreover, SMEs have limited resources. Prior (2007) suggests that CI is the key to SMEs' competitiveness.

\section{Definition of small and medium-sized enterprises}

According to the South African National Small Business Act 102 of 1996, 'small business' means a separate and distinct business entity (including co-operative enterprises and non-government enterprises) managed by one owner or more which, including its branches or subsidiaries (if any), is predominantly carried on in any sector or subsector of the economy and which can be classified as a micro-enterprise, a very small enterprise, a small enterprise or a medium enterprise.

\section{Classification of small and medium-sized enterprises}

The most widely used framework for SMEs in South Africa is set out in the South African National Small Business Act 102 of 1996, which defines five categories of enterprises in South Africa. The definition is based on the number of employees (the most common definition) per enterprise size combined with the annual turnover categories and the gross assets (excluding fixed property). The five enterprise categories are as follows:

1. Survivalist enterprise: The income generated is less than the minimum income standard or the poverty line. This category is considered pre-entrepreneurial, and includes hawkers, vendors and subsistence farmers. (In practice, survivalist enterprises are often categorised as part of the micro-enterprise sector).

2. Micro enterprise: The turnover is less than the VAT registration limit (that is, R150 000 per year). These enterprises usually lack formality in terms of registration. They include, for example, spaza shops, minibus taxis and household industries. They employ no more than 5 people.

3. Very small enterprise: These are enterprises employing fewer than 10 paid employees, except mining, electricity, manufacturing and construction sectors, in which the figure is 20 employees. These enterprises operate in the formal market and have access to technology.

4. Small enterprise: The upper limit is 50 employees. Small enterprises are generally more established than very small enterprises and exhibit more complex business practices.

5. Medium enterprise: The maximum number of employees is 100 , or 200 for the mining, electricity, manufacturing and construction sectors. These enterprises are often characterised by the decentralisation of power to an additional management layer. (Abor \& Quartey 2010)

\section{Competitive intelligence}

To better understand CI, one has to know how it is formulated (Bourret 2012). Processed data produces information; processed information produces knowledge; and processed knowledge produces wisdom and intelligence (Bernstein 2011). Data consists of raw facts (Stair \& Reynolds 2006). Information is a collection of facts organised in such a way that they have additional value beyond the value of the facts themselves (Stair \& Reynolds 2006). Stair and Reynolds (2006) define knowledge as an awareness and understanding of a set of information and ways in which information can be made useful to support a specific task or reach a decision. According to Taleghani et al. (2012), knowledge exists in many different forms in organisations. Some of these are tangible, whilst others are more subtle and intangible by nature. Wisdom is the human ability to learn from experience and adapt to changing conditions (Post \& Anderson 2003). Intelligence is a comprehensive ability to use one's existing knowledge or experience to adapt new situations or solve new problems (Shi 2011).

\section{Evolution of competitive intelligence}

Competitive intelligence is an amalgam of disciplines and evolved from economics, marketing, military theory, information science and strategic management (Juhari \& Stephens 2006). According to Muller (2005), CI took root in South Africa in the mid-1990s and early 2000s. Whilst CI is a relatively new management tool, it is evolving in complexity and importance to maintain pace with rapid business development (Heppes \& Du Toit 2009). Since the end of the Cold War, CI - once widely used in the military environment - has rapidly infiltrated into business environment (Deng \& Luo 2010).

\section{Definition of competitive intelligence}

There are numerous definitions for $\mathrm{CI}$ in practice and literature, and no single definition is likely to be precise and universally accepted (Fleisher \& Wright 2009). Brody (2008) argues that because $\mathrm{CI}$ is a process that is set in situations that are dynamic and in which the players are moving forward in a constantly changing business environment, the variety of definitions may be a reflection of the process of change. Brody's definition is adopted for the purpose of this study because it is broader and simpler than most CI definitions in the literature. Brody (2008) defines CI as:

the process by which enterprises gather actionable information about competitors and the competitive environment and, ideally, apply it to their planning processes and decision-making in order to improve their enterprise's performance. (n.p.)

\section{Competitive intelligence awareness}

Competitive intelligence growth depends on the creation of awareness of its benefits and a change in the way that enterprises deal with and view information (Muller 2007). In terms of awareness, one has to address knowledge, understanding, perceptions, etcetera. Smith et al. (2010) there 
is a dearth in the literature regarding the awareness and use of CI in SMEs. According to Muller (2005), the need for creating awareness of the benefits of CI is important. Awareness creation has been done with success in other countries through the cooperation between media advocacy groups, workshops, training enterprises, academic courses, and full support of and participation in $\mathrm{CI}$ activities by the government.

\section{Methodology}

A survey was undertaken to collect data from SMEs in the City of Tshwane Metropolitan Municipality (CTMM) of Gauteng Province in South Africa. The CTMM is the largest municipality in South Africa. It is the capital city of South Africa. Data was collected from one hundred SMEs from nine locations in the CTMM using a quota sample. A quota sample was undertaken due to time and financial constraints. Locations were sampled in order to cover both urban and rural areas of the CTMM. The sample consisted of $74 \%$ urban and 26\% rural SMEs in the CTMM. The locations included in the sample were Mabopane; Mamelodi; Soshanguve; GaRankuwa; Eersterust; Atteridgeville; Winterveld; Silverton or Pretoria East; Pretoria CBD and Rosslyn. Data were collected using a questionnaire. Questionnaires were hand-delivered to enterprises that do not have access to e-mail. For the SMEs that had access to e-mail, the questionnaire was sent to them via e-mail. The questionnaire had two sections. The aim of the first section was to collect biography of SMEs. The aim of the second section was establish the awareness and practice of CI by SMEs.

One hundred and fifty questionnaires were distributed to the respondents hoping that at least one hundred would be returned by the cut-off date. Indeed, one hundred usable questionnaires were received by the cut-off date. E-mail and phone calls were used to follow up on distributed questionnaire. This ensured that the required one hundred questionnaires were returned. Therefore the response rate was $66.67 \%$. The internal data reliability was calculated to be 0.806 (Cronbach' Alpha).

\section{Results}

Of these one hundred SMEs that participated in the survey, only one respondent $(1 \%)$ was a sole proprietorship; fourteen respondents (14\%) were partnerships; fifty five (55\%) were close corporations; and thirty (30\%) were companies. These forms of enterprises are defined by Nieman (2006) as follows: proprietorship: is an enterprise that has one owner and there is no distinction between the personal estate of the owner and the business estate. Partnerships: is an enterprise formed when a minimum of two and a maximum of 20 people conclude an agreement to do business as a partnership. Close corporation: is a separate legal entity and is regulated in terms of the South African Close Corporation Act 69 of 1994. The CC must be registered in term of this Act in order to attain separate legal entity status. A CC must have at least one member and not more than 10 members. Companies: is an association of people incorporated in terms of the Companies Act 61 of 1973. A company can have share capital or can be incorporated not for gain, in which case it will not have share capital. Eleven business sectors or subsectors were identified from the literature. Only two additional industries were added by respondents as others and these are: cleaning industry $(1 \%)$ and media and marketing $(1 \%)$. The remainder of the respondents are spread as follows:

- finance and business services (8\%)

- catering, accommodation and other trade (19\%)

- retail and motor trade and repair services (23\%)

- electricity, gas and water (2\%)

- community, social and personal services (18\%)

- wholesale trade, commercial agents and allied services (5\%)

- construction $(8 \%)$

- manufacturing (12\%).

Of the one hundred SMEs, fifteen (15\%) had 21-50 employees, thirty (30\%) had 11-20 employees, thirty six (36\%) had 6-10 employees and nineteen (19\%) had 1-5 employees. Concerning years of business operation, fifty (50\%) were operating for 6 or more years, thirty nine (39\%) were operating for $3-5$ years and only eleven $(11 \%)$ were in operation for $1-2$ years. With regard to annual turnover, two (2\%) SMEs were making a turnover between R6 million to R10 million, forty eight (48\%) were making a turnover of between R1m and R5m and the rest (50\%) were making less than R1m. Pertaining to owner or manager's educational qualification, five scales were identified, grade 8 to grade 10 , grade 11 to grade 12 , undergraduate diploma or degree, honours degree and masters or doctoral degree. Only five (5\%) of the respondents had masters or doctoral degree, twenty one (21\%) had honours degree, $47 \%$ had undergraduate diploma or degree and twenty seven $(27 \%)$ had grade 11 or grade 12 . Pertaining to owner or manager's years of working experience, only one $(1 \%)$ of the respondents had less than one year of working experience, four (4\%) had 1-2 years of working experience, fifty (50\%) had 3-5 years of working experience and $45 \%$ had 6 or more years of working experience. Table 1 indicates owner or manager's years of working experience.

To establish SMEs' practice and awareness of CI, a five-point Likert scale ranging from 'strongly disagree' to 'strongly agree' was used. Numbers $1-5$ we used with number 1 indicating 'strongly disagree' and number 5 indicating 'strongly agree'. Table 2 shows the different variables used to establish the awareness and practice of CI by SMEs. The aim of variable 1 was to establish whether the respondents were aware of CI. The mean was calculated as 4.12 and the standard deviation was 0.671 . The lower standard deviation indicates that there was less spread of responses to this question. The mean of

TABLE 1: Owner or manager's years of working experience.

\begin{tabular}{lcc}
\hline Years of working experience & Number of respondents & \% of respondents \\
\hline $3-5$ years & 50 & 50 \\
6 or more years & 45 & 45 \\
$1-2$ years & 4 & 4 \\
Less than 1 year & 1 & 1 \\
\hline Total & $\mathbf{1 0 0}$ & $\mathbf{1 0 0}$
\end{tabular}


4.12 indicates that nearly all of the respondents indicated that they were aware of CI. Variable 2 was intended to determine whether the respondents practiced $\mathrm{CI}$ in their businesses. The standard deviation of 0.687 reveals that there was less spread of responses to the question. Moreover, it indicates that more respondents concurred with the mean of 4.45. The mean reveals that the majority of the respondents agreed that they practice CI in their enterprises. Variable 3 was designed to determine whether the respondents had a formalised CI function. The higher standard deviation of 1.143 indicates that there was more spread of responses to this variable. Also, it points out that fewer respondents concurred with the mean. The mean of 2.16 indicates that most of the respondents disagreed with the statement. This means that most of the respondents did not have a formalised CI function. The reason behind variable 4 was to ascertain whether the respondents had a formalised CI process. The slightly higher standard deviation of 1.078 indicates that there was more spread of responses to this question. Moreover, it reveals that fewer respondents concurred with the mean. The mean of 2.01 indicates that most of the respondents disagreed with the statement, which means that they did not have a formalised CI process. The purpose of variable 5 was to ascertain whether the respondents hired people or other businesses to collect information on their behalf. The mean and standard deviation were 3.10 and 1.202 respectively. The high standard deviation indicates that there was more spread of responses to this question. The mean of 3.10 signifies that more respondents hired people or other businesses to collect information on their behalf. Variable 6 was intended to establish whether the respondents had a computerised CI system. The high standard deviation of 2.436 indicates that there was more spread of responses to this variable. The mean of 1.84 indicates that more respondents strongly disagreed with the statement. This means that most of the respondents did not have a computerised CI system.

The following strong positive linear correlations were established between variables in Table 3 and owners or managers years of working experience:

Pearson's coefficient of linear correlation $(r)$ for variables 1 and owners or managers years of working experience was 0.746 . Thus, there was a strong positive linear association between these two variables. The cross-tabulation (see Table 2) shows that all the respondents $(100 \%)$ with less than 1 year, three out of four $(75 \%)$ respondents with 1-2 years, 44 out of 50 (88\%) respondents with $3-5$ years, and 40 out of $45(88.89 \%)$ respondents with 6 or more years of working experience were aware of $\mathrm{CI}$. Thus, owners or managers with more years of working experience were to a larger extent aware of $\mathrm{CI}$ than those with fewer years of working experience.

Variable 2 and owners or managers years of working experience had a very strong positive linear association. Pearson's $r$ for this variable was 0.953 . The cross-tabulation (see Table 4 below) reveals that almost all the respondents with any number of years of working experience agree that they practiced CI. Thus, almost all the enterprises were practicing CI regardless of the owner or manager's years of working experience.

Variable 4 had very strong positive linear association with owners or managers years of working experience. Pearson's $r$ for this correlation was 0.926 . The cross-tabulation (see Table 5 below) shows that all the respondent (100\%) with less than 1 year, two out of four (50\%) respondents with 1-2 years, 38 out of $50(76 \%)$ respondents with $3-5$ years and 33 out of $45(73.33 \%)$ respondents with 6 or more years of working experience did not have a formalised CI process. Thus, most of the owners or managers with 3-5 years did not have a formalised CI process.

Pearson's $r$ for variable 5 and owners or managers years of working experience was 0.803 . Thus, there was a very strong positive linear association between these variables.

TABLE 2: Competitive intelligence awareness and practice variables.

\begin{tabular}{llll}
\hline $\begin{array}{l}\text { Variable } \\
\text { number }\end{array}$ & Variables for establishment of $\mathrm{Cl}$ awareness and practice & $\mathrm{M}$ & $\mathrm{SD}$ \\
\hline 1 & We are aware of competitive intelligence. & 4.12 & 0.671 \\
2 & We practice competitive intelligence in our business. & 4.45 & 0.687 \\
3 & $\begin{array}{l}\text { Our business has a formalised competitive intelligence } \\
\text { function. }\end{array}$ & 2.16 & 1.143 \\
4 & $\begin{array}{l}\text { We have a formalised competitive intelligence process. } \\
4\end{array}$ & 2.01 & 1.078 \\
& $\begin{array}{l}\text { We hire people or other businesses to collect information } \\
\text { on our behalf. }\end{array}$ & 3.10 & 1.202 \\
6 & We have a computerised competitive intelligence system. & 1.84 & 2.436 \\
\hline
\end{tabular}

$\mathrm{Cl}$, competitive intelligence; $\mathrm{M}$, mean; $\mathrm{SD}$, standard deviation.

TABLE 3: Correlation between awareness of competitive intelligence and owner or manager's years of working experience.

\begin{tabular}{lccccc}
\hline Variable 1 & \multicolumn{3}{c}{ Owner or manager years of working experience } & Total \\
\cline { 2 - 5 } & $\begin{array}{c}\text { Less than } \\
\mathbf{1} \text { year }\end{array}$ & $\mathbf{1 - 2}$ years & $\mathbf{3 - 5}$ years & $\begin{array}{c}\mathbf{6} \text { or more } \\
\text { years }\end{array}$ & \\
\hline Strongly disagree & 0 & 0 & 1 & 0 & $\mathbf{1}$ \\
Neutral & 0 & 1 & 5 & 5 & $\mathbf{1 1}$ \\
Agree & 0 & 3 & 30 & 29 & $\mathbf{6 2}$ \\
Strongly agree & 1 & 0 & 14 & 11 & $\mathbf{2 6}$ \\
\hline Total & $\mathbf{1}$ & $\mathbf{4}$ & $\mathbf{5 0}$ & $\mathbf{4 5}$ & $\mathbf{1 0 0}$ \\
\hline
\end{tabular}

TABLE 4: Correlation between competitive intelligence practice and owner or manager's years of working experience.

\begin{tabular}{lccccc}
\hline Variable 2 & \multicolumn{3}{l}{ Owner or manager years of working experience } & Total \\
\cline { 2 - 5 } & $\begin{array}{c}\text { Less than } \\
\text { 1 year }\end{array}$ & $\mathbf{1 - 2}$ years & $\mathbf{3 - 5}$ years & $\begin{array}{c}\mathbf{6} \text { or more } \\
\text { years }\end{array}$ & \\
\hline Strongly disagree & 0 & 0 & 1 & 0 & $\mathbf{1}$ \\
Disagree & 0 & 0 & 0 & 1 & $\mathbf{1}$ \\
Neutral & 0 & 0 & 1 & 1 & $\mathbf{2}$ \\
Agree & 0 & 3 & 20 & 21 & $\mathbf{4 4}$ \\
Strongly agree & 1 & 1 & 28 & 22 & $\mathbf{5 2}$ \\
\hline Total & $\mathbf{1}$ & $\mathbf{4}$ & $\mathbf{5 0}$ & $\mathbf{4 5}$ & $\mathbf{1 0 0}$ \\
\hline
\end{tabular}

TABLE 5: Correlation between competitive intelligence process formalisation and owner or manager's years of working experience.

\begin{tabular}{lccccc}
\hline Variable & \multicolumn{2}{l}{ Owner or manager years of working experience } & Total \\
\cline { 2 - 5 } & $\begin{array}{c}\text { Less than } \\
\mathbf{1} \text { year }\end{array}$ & $\mathbf{1 - 2}$ years & $\mathbf{3 - 5}$ years & $\begin{array}{c}\mathbf{6} \text { or more } \\
\text { years }\end{array}$ & \\
\hline Strongly disagree & 1 & 0 & 22 & 17 & $\mathbf{4 0}$ \\
Disagree & 0 & 2 & 16 & 16 & $\mathbf{3 4}$ \\
Neutral & 0 & 1 & 7 & 5 & $\mathbf{1 3}$ \\
Agree & 0 & 1 & 4 & 6 & $\mathbf{1 1}$ \\
Strongly agree & 0 & 0 & 1 & 1 & $\mathbf{2}$ \\
\hline Total & $\mathbf{1}$ & $\mathbf{4}$ & $\mathbf{5 0}$ & $\mathbf{4 5}$ & $\mathbf{1 0 0}$ \\
\hline
\end{tabular}


The cross-tabulation (see Table 6 below) shows that all the respondent (100\%) with less than 1 year, two out of four (50\%) respondents with 1-2 years, 26 out of 50 (52\%) respondents with 3-5 years, and 28 out of $45(62.22 \%)$ respondents with 6 or more years of working experience agreed that they hired people or other businesses to collect information on their behalf. Thus, more respondents with 6 or more years of experience outsourced CI than those with fewer years of working experience.

There was a very strong positive linear association between variable 6 and owners or managers years of working experience. Pearson's $r$ for this correlation was 0.913. The crosstabulation (see Table 7 below) shows that all the respondent $(100 \%)$ with less than 1 year, all the respondents (100\%) with $1-2$ years, 46 out of $50(92 \%)$ respondents with $3-5$ years and 28 out of $45(62.22 \%)$ respondents with 6 or more years of working experience did not have computerised CI. Thus, most respondents with $3-5$ years working experience did not have computerised CI.

\section{Discussion}

With most SMEs' owners or managers having a degree or diploma, they could use this formal knowledge to manage their enterprises. Additionally, the many years of working experience meant that the owners or managers were exposed to different business situations in their enterprises. With a diploma or degree and 3-5 years of working experience, it's no surprise that most of the SMEs have been in operation for 6 or more years. It is evident from the findings that SMEs contribute to job creation because majority of these SMEs employed 6-10 employees.

Although it is evident from the findings that these SMEs are aware of $\mathrm{CI}$ and practice it, they practice CI informally. Most of these SMEs did not have formalised CI process and function. Moreover, they do not have computerised CI system. Perhaps this could be because of the fact that SMEs

TABLE 6: Correlation between competitive intelligence outsourcing and owner or manager's years of working experience.

\begin{tabular}{lccccc}
\hline Variable 5 & \multicolumn{3}{l}{ Owner or manager years of working experience } & Total \\
\cline { 2 - 5 } & $\begin{array}{c}\text { Less than } \\
\mathbf{1} \text { year }\end{array}$ & $\mathbf{1 - 2}$ years & $\mathbf{3 - 5}$ years & $\begin{array}{c}\mathbf{6} \text { or more } \\
\text { years }\end{array}$ & \\
\hline Strongly disagree & 0 & 1 & 11 & 4 & $\mathbf{1 6}$ \\
Disagree & 0 & 1 & 9 & 7 & $\mathbf{1 7}$ \\
Neutral & 0 & 0 & 4 & 6 & 10 \\
Agree & 1 & 2 & 24 & 28 & 55 \\
Strongly agree & 0 & 0 & 2 & 0 & $\mathbf{2}$ \\
\hline Total & $\mathbf{1}$ & $\mathbf{4}$ & $\mathbf{5 0}$ & $\mathbf{4 5}$ & $\mathbf{1 0 0}$ \\
\hline
\end{tabular}

TABLE 7: Correlation between computerisation of competitive intelligence and owner or manager's years of working experience.

\begin{tabular}{lccccc}
\hline Variable $\mathbf{6}$ & \multicolumn{2}{l}{ Owner or manager years of working experience } & Total \\
\cline { 2 - 5 } & $\begin{array}{c}\text { Less than } \\
\mathbf{1} \text { year }\end{array}$ & $\mathbf{1 - 2}$ years & $\mathbf{3 - 5}$ years & $\begin{array}{c}\mathbf{6} \text { or more } \\
\text { years }\end{array}$ & \\
\hline Strongly disagree & 1 & 2 & 26 & 21 & $\mathbf{5 0}$ \\
Disagree & 0 & 2 & 19 & 17 & $\mathbf{3 8}$ \\
Neutral & 0 & 0 & 4 & 7 & $\mathbf{1 1}$ \\
\hline Total & $\mathbf{1}$ & $\mathbf{4}$ & $\mathbf{5 0}$ & $\mathbf{4 5}$ & $\mathbf{1 0 0}$ \\
\hline
\end{tabular}

are small by nature and lack resources. Whilst the existing literature suggests that awareness of CI must be raised, the findings of this study reveal that the SMEs are aware of CI.

The findings reveal that SMEs' owners or managers with many years of working experience are more aware of CI than those with fewer years of working experience. Also, SMEs whose owners or managers have many years of working experience practice CI more than those with fewer years of working experience. Moreover, SMEs whose owners or managers have many years of working experience outsource $\mathrm{CI}$ than those with fewer years of working experience. This is because these managers or owners have been exposed to the turbulent business environment long enough to realise the strategic tools needed to survive. However, owners or managers with many years of working experience do not have formal CI processes and their CI is not computerised. Perhaps this is because of SMEs lack financial resources. Therefore, owners or managers' years of working experience has a greater influence on CI awareness and practice.

\section{Conclusion}

Although SMEs are a major contributor to a country's GDP, high competition makes it difficult for SMEs to survive. In order to survive and sustain their businesses, SMEs have to seek and obtain competitive advantage over their rivals. Competitive intelligence has been identified to provide enterprises with competitive advantage. This is because CI provides enterprise managers with information regarding their competitive environment and hence enables decisionmaking. Although there are pleas to raise awareness of $\mathrm{CI}$ amongst SMEs, the current study reveals that these SMEs are aware of CI. These SMEs are not only aware of CI but they also practice it. However, this study concurs with current literature in that SMEs practice CI informally (Muller 2005). This is evident in that these SMEs don't have formalised CI process and function. Moreover, these SMEs do not have computerised CI system. Also, just like larger enterprises, SMEs outsource CI to either individuals or other enterprises. We can therefore conclude that these SMEs are aware of $\mathrm{CI}$ and practice it informally.

The purpose of this research was to establish the influence of owner or manager's working experience on competitive intelligence practice and awareness of SMEs. Importantly, the study established that owners or managers with many years of working experience are more aware of $\mathrm{CI}$ and practice it than those with fewer years of working experience. Moreover, owners or managers with many years of working experience outsource CI more than those with fewer years of working experience. Therefore, SMEs owners or managers' years of working experience has a greater influence on awareness and practice of CI. Put differently, years of working experience is a great predictor of $\mathrm{CI}$ awareness and practice.

It was not the purpose of this research to establish what type of working experience influence the awareness and practice 
of CI. It was also not the purpose of this study to establish the kinds of qualification required to practice CI. Future study should be undertaken to establish the type of working experience that influence CI awareness and practice. Also, future study should be conducted to establish why SMEs do not formalise CI. A future study should be conducted to establish the influence of practicing CI informally on the success of SMEs.

\section{Acknowledgement}

The authors would like to acknowledge the University of South Africa (South Africa) for the funding and support without which this research would not have been possible.

\section{Competing interest}

The authors declare that they have no financial or personal relationship(s) which may have inappropriately influenced them in writing this article.

\section{Authors' contributions}

T.E.N. (University of South Africa) initiated this research; conduct literature review; analysis; and conclusion. R.P. (University of South Africa) led and supervises this project, selected the journal and handled editorial matters.

\section{References}

Abor, J. \& Quartey, P., 2010, 'Issues in SME development in Ghana and South Africa', International Research Journal of Finance and Economics 1(39), 218-228.

Bernstein, J.H., 2011, The Data-Information-Knowledge-Wisdom Hierarchy and its Antithesis, viewed 14 May 2012, from https://journals.lib.washington.edu/index. $\mathrm{php} /$ nasko/article/viewFile/12806/11288

Bourret, C., 2012, 'Standards, evaluation, certification and implications for the study of competitive intelligence', Journal of Intelligence Studies in Business 2(1), 59-67.

Brody, R., 2008, 'Issues in defining competitive intelligence: An exploration', Journal of Competitive Intelligence and Management 4(3), 3-16.
Deng, Z. \& Luo, L., 2010, 'An exploratory discussion of new ways for competitive intelligence on Web2.0', International Federation for Information Processing 252(1), 597-604.

Fleisher, C.S. \& Wright, S., 2009, 'Examining differences in competitive intelligence practice: China, Japan, and the West', Thunderbird International Business Review 51(3), 249-261. http://dx.doi.org/10.1002/tie.20263

Guarda,T., Augusto, M. \& Silva, C., 2012, 'Competitive advantage in e-commerce: the case of database marketing', Advances in Intelligent and Soft Computing 143(1) 123-130. http://dx.doi.org/10.1007/978-3-642-27966-9_18

Heppes, D. \& Du Toit, A., 2009, 'Level of maturity of the competitive intelligence function: Case study of a retail bank in South Africa', Aslib Proceedings: New Information Perspectives 61(1), 48-66.

Juhari, A.S. \& Stephens, D., 2006, 'Tracing the origins of competitive intelligence through history', Journal of Competitive Intelligence and Management 3(4), 61-82.

Koseoglu, M.A., Karayormuk, K., Parnell, J.A. \& Menefee, M.L., 2011, 'Competitive intelligence: Evidence from Turkish SMEs', International Journal of Entrepreneurship and Small Business 13(3), 333-349. http://dx.doi.org/10.1504/IJESB.2011.041664

Muller, M.L., 2005, 'Beyond competitive intelligence-innovation and competitive strategy', South African Journal of Information Management 7(1).

Muller, M.L., 2007, 'Competitive intelligence in business: Latin America', South African Journal of Information Management, 9(2).

Nieman, G., 2006, Small business management: A South African approach, Van Schaik, Pretoria.

Olawale, F. \& Garwe, D., 2010, 'Obstacles to the growth of new SMEs in South Africa: A principal component analysis approach', African Journal of Business Management 4(5), 729-738.

Post, G.V. \& Anderson, D.L., 2003, Management Information Systems: Solving Business Problems with Information Technology, 3rd edn., McGraw-Hill/Irwin, Boston.

Prior, V., 2007, 'DYI detection: Competitive intelligence for SMEs', viewed 18 November 2010, from http://web.fumsi.com/go/article/manage/2483

Shi, Z., 2011, 'Foundations of Intelligence Science', International Journal of Intelligence Science 1(1), 8-16. http://dx.doi.org/10.4236/ijis.2011.11002

Shih, M., Liu, D.R. \& Hsu, M., 2010, 'Discovering competitive intelligence by mining changes in patent trends', Expert Systems with Application 37(4), 2882-2890. http:// dx.doi.org/10.1016/j.eswa.2009.09.001

Smith, J.R., Wright, S. \& Pickton, D., 2010, 'Competitive intelligence programmes for SMEs in France: Evidence of changing attitudes', Journal of Strategic Marketing 18(7), 523-536. http://dx.doi.org/10.1080/0965254X.2010.529154

South African Government, Close Corporation Act 69 of 1994, viewed on 23 June 2012, from http://www.justice.gov.za/legislation/acts/1984-069-CCorp.pdf

South African Government, National Small Business Act 102 of 1996, viewed 18 November 2010, from http://www.info.gov.za/acts/1996/a102-96.pdf

Stair, R. \& Reynolds, G., 2006, Principles of information systems, Thompson Course Technology, Boston.

Taleghani, M., Rad, S.K. \& Rahmati, Y., 2012, 'The Role of Innovation in the Relationship between Knowledge Management and Competitive Advantage (An Empirical Study of Tourism Industry)', Journal of Basic and Applied Scientific Research 2(4), 3607-3614.

Tarraf, T. \& Molz, R., 2006, 'Competitive intelligence at small enterprises', SAM Advanced Management Journal 71(4), 24-34. 